\title{
Health Economics Policy and Law
}

Getting involved: The extent and impact of patient and public involvement in the Swedish health system

Mio Fredriksson, Uppsala University

Jonathan Tritter, Aston University

\section{Abstract}

Patient and public involvement is framed as beneficial for individuals and for the health system. However, little is known about the extent of involvement, or of its impact. Based on data from Sweden, we show that apart from voting in regional elections (76\%), more people reported involvement as individual patients (23\%) than part of collective activities (5\%) or activities relating to a citizen perspective (4\%). There was no correlation between how many people participated and the estimated impact - which was generally low. More extensive involvement is thus not linked to the potential to influence decisions. We argue that to achieve the benefits associated with patient and public involvement it is crucial to understand more about people's motivation for being involved and what underlies low estimates of impact. This requires a more systematic approach to PPI-policies, how they are evaluated and their results communicated to participants and the society. We also argue that a future challenge for the Swedish health system, and for other similar health systems, is to support long-term collective involvement in the midst of growing individualization of health services and involvement opportunities primarily intended for patients. 


\section{Introduction}

Patient and public involvement in healthcare (PPI) has become increasingly important in European health systems (Coulter, 2005, 2011; Dent \& Pahor, 2015; Florin \& Dixon, 2004; Ocloo \& Matthews, 2016; Anonymous, 2009). PPI may be defined as the "active participation of citizens, users and carers and their representatives in the development of healthcare services and as partners in their own healthcare" (BMA, 2015). Involvement is framed as positive for individuals, the health system, public health, as well as for communities and society as a whole (Coulter \& Ellins, 2006). There are a wide range of motives for involvement - from empowerment of patients and disadvantaged service users, strengthening democratic accountability and responsiveness - to improving service delivery effectiveness, and health outcomes (Coulter, 2005, 2011; Crawford, 2003; van Thiel \& Stolk, 2013). These motives are mirrored in the variety of involvement activities facing patients and the public today in European health systems; activities with different aims, scope for participation in actual decision-making and level of control over decisions. Yet, the literature contains little evidence on the extent of involvement or of its impact, which is assessed in this article. Previous research has shown that although people generally feel it is important to have the opportunity to participate, for example in health prioritization decisions, relatively few actually participate (Litva et al., 2002; Rosén, 2006). Furthermore, there is a lack of research about the impact of PPI, for example how services and service outcomes have changed of involvement. In a review, Mockford et al. concluded that a primary limitation of the evidence base 
on PPI is the poor quality in reporting the impact and lack of robust measurement (Mockford et al., 2012). Lack of evidence on impact has also been established in relation to PPI in research (Brett et al., 2014a; Brett et al., 2014b; Staniszewska et al., 2008). However, defining impact is complex as it is dependent of factors such as the purpose of involvement, organizational culture, policy, people and resources (Mockford et al., 2012); impact is highly context dependent and comparisons between different activities, health systems or settings not straightforward. Yet, a broad dividing line can be drawn between extrinsic and intrinsic effects, or impact (Brannan et al., 2006). In this article, we focus on extrinsic effects, which are about optimizing the consequences of decisions in terms of individual and societal benefits, i.e. a means to an end such as the achievement of effectiveness and efficiency-policies in health care (Christiaens et al., 2012). Intrinsic effects or benefits are about empowerment or capacitating the individuals, and the process of participation is thus seen as a good in and of itself (Brannan et al., 2006).

\section{When studying the extent of involvement, it is important to consider activities}

framed towards patients as well as the public in a more broad sense. Although often referred to interchangeably in policy-making and research, patients and the public (often referred to as citizens) occupy two distinct ideal-type roles in relation to the health service; that of the 'health service user' and that of the 'public policy agent' (Charles \& DeMaio, 1993; Anonymous, 2017). This is not a distinction between people - who may adopt the role of patient or citizen in different contexts - but between interests (Anderson et al. 2002): which may contrast between patients and the public (Anonymous, 2017; Peeters and Stiggelbout 2010). Put simply, it is the distinction "between what we want when 
we are using the health service and what we hope for as citizens or taxpayers" (Coulter 2006, p. 28). Thus, the rationales for involving patients differs from involving the public (Warsh, 2014) and involvement associated with the two roles have different potential scope. Typically, patient involvement aims at personal decisions about the individual's own care and seeks to improve individual health outcomes and satisfaction, but may also refer to a group of patients helping to shape a particular service (Coulter, 2011; Florin \& Dixon, 2004). In contrast, public involvement aims to take account of broader public interests and is associated with service development; i.e. strategic decisions about health services and policy at local or national level that address societal values and public health, determining health service priorities etc. (Florin \& Dixon, 2004). For patients the aim of involvement is often improvements in clinical care or culture, while for members of the public the aim is organizationalor general policy changes. Thus, the distinction between patients and the public is also important to keep in mind when investigating the impact of involvement, but, in practice, it is less clear.

In this article, we present the findings from the first national survey in Sweden of both patient and public involvement activities in relation to health. We have found no comparable studies internationally. Public involvement activities such as those investigated here, are usually studied by political scientists interested in the functioning of participatory democracy, while health service researchers interested in the patient-clinician interaction and health outcomes study patient involvement and empowerment. However, in health systems such as in Sweden where regional governments have dual functions - being both democratic arenas and service-provision organizations resolving collective needs and 
interests (Amnå, 2006) - these two research areas converge. Exploring PPI in this context helps us establish the link between these dual functions. More specifically the aim of this study was to investigate the extent to which people have been involved in a range of involvement activities and their assessment of the impact of their involvement. The study thus investigates the perceptions of involved individuals, not the nature or actual impact of the involvement, which is the next step to investigate in this research field.

\section{$\underline{\text { Sweden: the case }}$}

In Toth's (2016) terminology, Sweden is a tax-based universalist health system which was previously integrated but is becoming increasingly separated due to policies supporting private provision and patient choice. In addition, Swedish healthcare is highly decentralized. The responsibility for healthcare is divided between three directly elected governing levels (Anell et al., 2012). The Swedish state is responsible for the overall healthcare policy and in the past ten years conscious efforts have been made to strengthen the position of the patient; examples are the introduction of choice of primary care provider in 2010 and Sweden's first Patient Law coming into force in 2015. The responsibility for the funding and provision of healthcare and dental care rests with the 21 selfgoverning county councils/regions - hereinafter referred to as regions - and this is their major task requiring $90 \%$ of their budget. Also self-governing and locally elected, the municipalities are responsible for care for the elderly and those with disabilities. 
In contrast to patient involvement, which has been the focus of national policy efforts, the regions handle issues of public involvement. Public involvement is channeled through the regional democratic system with representatives elected every four years; this implies that decision-making on healthcare is based on public interest (Magnussen et al., 2009). Public involvement is generally framed as a way to influence the political process and decisions within the regions. To increase people's opportunities to be involved between regional elections and in more practical aspects of service planning and delivery, more participatory forms of public involvement ('democratic innovations' (Lundell et al., 2016)) have gradually emerged (Arvidsson et al., 2015).

Generally, Sweden is a country with a vital civil society, high membership in voluntary associations (Trägårdh, 2007), and where participation is a fundamental characteristic of the health system (Magnussen, 2009): mainly carried out through the regional representative political system. Patientcenteredness and patient's rights are however weak in comparison to health systems in other high-income countries (Docteur et al., 2012; Winblad \& Ringard, 2009). While Sweden is often portrayed as a National Health Service (NHS) system, it is in fact largely decentralized. Sweden is a particular case but our findings have significant implications for other Nordic countries and countries with tax-based universalist health systems, in particular those governed locally or regionally. To what extent our findings apply to social health insurance systems (SHI) is an empirical question. Some elements of involvement are similar while some diverge. For instance, the same type of development with a strengthening of patient rights and a change of the individual's role from a passive consumer towards a more active participant can be noted within both 
system types (Sawicki and Bastian, 2008; Wildner et al., 2004). Simultaneously, it is common with participation by the insured in the health insurance funds (Wildner at al., 2004), and in Germany, in particular, patient involvement through self-help groups (Forster and Kranich, 2007; Härter et al, 2011) has developed significantly at the national level and the level of federal states (Kofahl et al., 2014) and gained increasing influence in the decision-making bodies of the SHI system (Busse and Blümel, 2014; Rojatz and Forster, 2017). As in Sweden, collective patient engagement in Germany is focused on the policy level, while it is focused at the provision level in the Netherlands and in England (Haarmann, 2018); illustrating crossovers between NHS and SHI systems in terms of involvement.

\section{Methods}

Sample and survey questions

The data comes from a Swedish telephone omnibus survey carried out by TNS Sifo in late January 2016. The sample includes 1500 members of the public, aged 15 years and over. The initial response rate among randomly selected residents in different regions was 35\%. Substitute respondents were sought in pre-defined strata for those individuals that denied participation or that could not be reached after multiple attempts. Data was weighted by gender, age, working status and area code to be representative of the Swedish population (see Table 1 for sample characteristics). While not perfect, this is a common approach to reduce nonresponse bias (Wolf, et al., 2016). On behalf of the authors, two questions 
investigating the extent of patient and public involvement as well as its impact, or effect, were included in the survey, see Table 2 . The 15 involvement activities investigated were compiled from previous regional investigations of involvement in Sweden and from official information material on opportunities for people to influence regional healthcare. They differ in aims and method and are an illustration of the broad range of activities present in health systems today. The order of the 15 involvement activities was rotated to avoid response bias.

//Table 1 and Table 2//

Ethics statement

The researchers had access only to the anonymized sample and thus no access to personal identifiable data. The data-set contained no sensitive personal information such as information about ethnicity, political orientation or health.

Data analysis and presentation

To investigate the extent of involvement as well as the estimated impact data was analysed descriptively and percentages and means presented with $95 \%$ confidence intervals. Confidence intervals that did not overlap indicated that the real values within the population were significantly different (Greenland et al., 2016). Tables and Figures present the weighted data. Correlations were tested using Pearsons $r$. 
In some cases data was grouped into clusters or indices to distinguish between 1) unit of participation: differentiating between individual and collective activities, that is whether people contribute with individual opinions or votes, or are approached, deliberate or act collectively as a group (Michels, 2011; Anonymous, 2009), and 2) involvement role: differentiating between patients and citizens, which e.g. have different roles, perspectives and interests (sectional vs societal interests) (Anonymous, 2017). In relation to the indices the mean scores refer to the mean percentage of respondents taking part in e.g. an individual or a collective activity (extent) and their mean estimate of the impact for the same index of activities.

In our analysis we also distinguish between representative and participatory activities and between activities based on 'exit' and 'voice' respectively (Hirschman, 1970). As voting is an activity that can be carried out only every four years and is distinct as it serves to elect representatives rather than involving people themselves, findings are presented both including and excluding voting. Furthermore, changing healthcare provider is also an activity distinct from the other activities. It builds on the opportunity to 'exit' ('choice' is often used synonymously) which frames the patient as a consumer and implies the possibility of withdrawing from a relationship. This is in contrast — with 'voice' that transforms individuals and groups from consumers to citizens with a right to engage in decision-making processes (Dent \& Pahor, 2015; Anonymous, 2013).

\section{Results}

Extent of involvement 
The results show that the majority of the respondents of voting age (76\%) had taken part in regional elections, Figure 1. Among the activities carried out between elections four were more extensively used to influence healthcare: replying to a patient survey (36\%), changing healthcare provider to get better care (29\%), signing a petition (28\%) and talking directly to healthcare professionals about the need for changes (20\%). Only 6 of 15 involvement activities had ever engaged more than $10 \%$ of the respondents. See Supplementary file for additional information.

//Figure 1//

When grouping the activities into indices based on unit of participation and the involvement role, the participation in individual activities was more extensive $(\bar{x}$ 20.10\%) compared to collective activities ( $\bar{x}$ 05.16\%), see Figure 2 . There was a large difference between being involved as an individual citizen $(\bar{x} \quad 2.86 \%$ excluding voting) and as an individual patient ( $\bar{x} 20.54 \%$ excluding changing provider). Overall the patient involvement activities attracted the most participants ( $\bar{x} 18.88 \%)$; more than public/patient activities $(\bar{x} 12.40 \%)$ and public activities both excluding voting ( $\bar{x}$ 03.69\%) and including voting $(\bar{x} 17.07 \%)$.

//Figure 2// 
During the last 12 months none of the activities intended to influence healthcare decisions or provision engaged more than $15 \%$ of the respondents, and 9 of 14 activities involved less than $5 \%$, see Supplementary file. As shown in Table 3, more than half of the respondents (56.9\%) had not engaged in any of the involvement activities available in the last 12 months. By contrast $19.7 \%$ of respondents had been involved in at least 2 activities during the same time period, and $2.7 \%$ of respondents had been involved in 5 or more activities. At any time in their life, 129 of the respondents had engaged in 5 or more participatory activities (8.6\%), and $640(42.7 \%)$ in at least 2 activities. Looking only at those activities oriented towards citizens or members of the public (voting excluded), about $90 \%$ had not been engaged at all over the last 12 months while about $10 \%$ had been involved in 1-2 activities. Including also voting in local elections, about $12 \%$ had never engaged in any type of involvement activity, and half of the respondents (50\%) reported being engaged in 1-2 activities in their life.

//Table 3//

Impact of involvement

The respondents generally estimated the impact of their involvement to be rather low. As shown in Figure 2, 7 of the 15 activities (all individual) had an estimated mean impact between 2.4 and 3.0 out of 10 , and 7 activities had an estimated mean impact between 3.5 and 4.3. Only one activity, changing healthcare provider, had an effect in the upper half of the effect scale $(\bar{x} 6.0 \mathrm{CI}[5.63,6.28])$. No effect at all ( 0 out of 10 ) was the mode answer in relation to all involvement 
activities, and a relatively large share also replied they did not know if their involvement had any effect ( 4 - $35 \%$ ). Thus, a relatively large share did not know or answered that their involvement had no effect at all (22 - 68\%), see Supplementary file.

Looking at the four 'between-election activities' that had ever engaged more than $20 \%$ of the respondents we find activities with varying degree of estimated impact, Figure 1. Two of these activities had a low estimated impact; $36 \%$ had replied to a patient survey but only $51 \%$ of them estimated it had had any effect $(\bar{x} 2.5)$ and $28 \%$ had signed a petition but only $50 \%$ of them estimated it had had any effect $(\bar{x} 2.9)$. The other two of the activities engaging the most respondents had a higher impact; $29 \%$ had changed healthcare provider to get better care and as many as $78 \%$ of them estimated it had an impact $(\bar{x} 6.0)$, and $20 \%$ had talked directly to staff about the need for changes: $58 \%$ of them estimated it had an impact $(\bar{x}$ 3.7). Overall, there was no correlation between the extent of involvement and the estimated impact (Pearson's $r,-0.080$, sig. 0.776).

When grouping the activities into indexes (Figure 2), we see that the estimated mean impact for patient activities $(\bar{x} 3.84)$ was higher compared to activities carried out by either patients or citizens ( $\bar{x} 2.88 \mathrm{CI}$ ), or citizens only $(\bar{x} 2.66)$. However, looking only at 'voice' activities (excluding changing provider which is an exit option) the mean estimated impact of patient, patient/citizen and citizen activities was similar. The mean estimated impact of citizen activities was significantly lower when including voting ( $\bar{x} 2.66$ compared to $\bar{x} 3.40)$. Furthermore, the collective involvement activities were estimated to have a 
slightly higher mean impact compared to the individual activities $(\bar{x} 3.69$ compared to $\bar{x} 3.11$ ); the difference being larger when only including voiceactivities ( $\bar{x} 3.69$ compared to $\bar{x} 2.63)$.

\section{Discussion}

How widespread is patient and public involvement in healthcare in Sweden? Our findings show that about $43 \%$ of the respondents had been involved in some type of involvement activity in the last 12 months and 10\% had never been involved even including voting in regional elections, which was the single involvement activity engaging the highest number of respondents. Under $10 \%$ of the respondents had engaged in more than five activities throughout their life (13\% if including voting), a category that might well be referred to as the 'usual suspects' (Beresford, 2013). Overall, the extent of patient involvement was significantly higher than citizen involvement, even if voting is included. With the exception of election years, the involvement activities that respondents primarily had engaged in to influence healthcare decisions and provision were individual and mainly patient focused, which may well be reasonable within a health system. Over the last 12 months, about $90 \%$ of the respondents had not been involved in any citizen-oriented activities (the last regional election was 2014, the next is 2018). Thus, between elections there seems to be a greater challenge participating as a citizen - a 'public policy agent', compared to as a patient - a 'health service user'. Thus, between elections, involvement in healthcare seems to be more directed towards improving individual health outcomes and satisfaction rather than improving the systems' effectiveness, responsiveness and accountability (Coulter \& Ellins, 2006; Forbat et al., 2009). Whether the 
extent of participation reported here is widespread or limited in comparison to other health systems is difficult to establish, as there are no comparative numbers available. However, it is important to note that the vast majority of the $43 \%$ of respondents that had been involved in the last 12 months participated in activities such as replying to patient surveys, changing provider and signing petitions - activities that require little time and effort. For instance, changing the provider only requires a few minutes making a telephone call or logging onto a web portal, and signing a petition can even be done in a few seconds. Furthermore, there is no a priori established definition of an adequate level of involvement, which would among other things be dependent on people's satisfaction with the health system and the actual quality of the services. While some would argue the higher degree of involvement the better as it empowers and capacitates individuals and increases effectiveness in the health system, it could potentially mean that patients and citizens are dissatisfied with the health system and try to find ways of expressing that. This is perhaps best illustrated with the growing number of patient complaints in Sweden (Skålén et al., 2013), which may be useful as a source for quality improvement, but may simultaneously indicate that people are dissatisfied with the services they get. As a declining share of the Swedish population think the health system works well on the whole - a drop from $44 \%$ in 2010 to $31 \%$ in 2016 , compared to $60 \%$ in Germany in 2016 (The Swedish Agency for Health and Care Services Analysis, 2016)- it seems important to provide a range of opportunities for citizens and patients to be involved in individual as well as collective activities to improve health system functioning. 
Most involvement activities have little impact

Most activities in our study were estimated by those who had been involved as having relatively low impact and all except for two of the activities were found in the interval of $\bar{x} 2.4-3.9$ out of 10 . From this it is impossible to establish 'actual' impact, but it suggests that people generally feel they have little opportunity to actively influence decisions in healthcare and the care provided by health centers, hospitals and the like. This may be problematic as one of the aspects that determines whether people participate or not is that people believe that their involvement is making a difference (Lowndes et al., 2006). Another aspect would be low barriers for involvement, as discussed below. Furthermore, for the most frequently occurring activities, $42 \%-50 \%$ of the respondents believed that their involvement had no impact or they did not know if it had an impact. This suggests that there is poor feedback from decision-makers and staff to those who participate in activities to influence policy or service provision. One conclusion is that the communication of results of involvement needs to be more transparent and directed at those who are involved if people are to be encouraged to feel that their involvement makes a difference.

Furthermore, there was no correlation between the extent of involvement and the estimated impact. Some of the involvement activities with the lowest estimated impact were among the activities participated in by the greatest number of respondents, for example replying to patient surveys and signing petitions. Thus, our study indicates that prompted involvement activities based on a response to a request, are associated with a comparatively higher degree of participation. These activities have a low barrier to participation (c.f. Garcia- 
Dominic et al., 2010); it does not require much time and little cost for the individual, and is a one-off effort. Thus, our findings align with observations from the UK where there is evidence that people prefer to be involved in health through relatively passive forms of one-off mechanisms and very few are prepared to participate in in-depth activities (Martin \& Boaz, 2000). Face-to-face commitment at specific times is suggested especially demanding (Lundell et al., 2016). The preference for participation in low-barrier activities is illustrated by our finding that few respondents had been involved in collective activities such as working in a political party (7\%) or a patient association (4\%) which usually require a more continuous and long-term involvement effort (c.f. Lundell et al., 2016). These two activities were, however, estimated to have a relatively high impact: $\bar{x} 3.9$ and $\bar{x} 4.3$ respectively. Yet, it should be noted that some collective activities build on representation, e.g. in citizen councils, which greatly reduces the number of people that can be involved, thus making comparisons between the extent of individual and collective involvement complex.

Recent comparisons based on The Commonwealth Fund's 2016 International $\underline{\text { Health Policy Survey of Adults in } 11 \text { countries show that Sweden permorms }}$ poorly compared to other high-income countries when it comes to patient information and involvement in decisions about care and treatment (The Swedish Agency for Health and Care Services Analysis, 2016). Our results suggest that the efforts to strengthen the weak position of Swedish patients (Docteur et al., 2012; Winblad \& Ringard, 2009) may have had an effect, at least on the relative extent of involvement of individual patients, but not necessarily on the perceived impact of involvement. However, one activity stands out with the highest estimated impact - changing healthcare provider to get better care 
$(\bar{x} 6.0)$ - which was also one of the most frequently reported activities to influence decisions in healthcare. This is the only activity that builds on 'exit' rather than 'voice'. In the Nordic countries patients have been pushed to take a more active role through choice of provider (Magnussen, 2009) and the intention behind making choice of primary care provider obligatory in all Swedish regions in 2010 was to strengthen the patients' position and their possibility to influence healthcare through the exit-option (Anonymous et al., 2013). Thus, our results suggest that patient choice has had an empowering effect. At the same time, it is important to note that it has been questioned if patient choice is a form involvement as the patient becomes a consumer navigating a market rather than being actively involved in priority setting or decision-making for the health system (Dent \& Pahor, 2015). In the Swedish context it has also been suggested that this kind of effort to empower patients may not only affect patients' chances of influencing healthcare but also those of citizens, who may lose collective 'voice' as a result (Anonymous, 2013). This type of market-based model provides no aggregation of preferences, no deliberation or debate, no discussion on political objectives and questioning of political priorities, only the expression of individual preferences to service providers (Pierre, 2009). Thus it is unlikely to inform collective prioritization within health systems. However, more recently some scholars have argued that increasing opportunities for choice leads citizens to be more favourably oriented towards voice (Pierre and Røiseland, 2016); our study does not include a temporal element so cannot make a judgement about the interaction effects between different types of involvement activities. 
Challenging the traditional model of involvement

A key aspect of the politically governed and decentralised Swedish health system is the institutionalization of arenas for local and regional democratic decisionmaking (Magnussen, 2009), which will serve to balance the diverse interests of the public and ensure common priorities (Urbinati \& Warren, 2008; Anonymous, 2017). The act of voting is admittedly individual, but its purpose is to establish the composition of a representative assembly that governs the regions' affairs on behalf of citizens. The Assembly has the power to make decisions on a collective basis - for example in which hospitals certain operations are performed, eligibility requirements for various treatments or how much money is spent on primary care - and voting in elections is assumed to be the most important mechanism for public involvement. The Swedish emphasis on voting as a mechanism to influence local and regional decisions in health and social care is noticeable in that Sweden ranks high in voter turnout in Europe $182 \%$ and $83 \%$ voted in regional and local elections respectively in 2014 in comparison to e.g. 34 \% in local elections in England in 2016), but less so on engagement in local/regional participatory democracy (European Commission, 2013). Nevertheless, in our sample, $51 \%$ of respondents who had voted in regional elections did not know or thought this activity had no impact. The rest of the respondents rated voting in regional elections, on average, as having little impact $(\bar{x} 2.7$ out of 10$)$. This constitutes a challenge to the traditional representative involvement model and to the system's legitimacy. Lister and Pia (2008), for instance, argue that it is necessary (but not sufficient) for democracy to function that people participate in elections. Elections are the main way of aggregating the individuals' expressed political opinions, which means a collective decision may 
be reached based on individual preferences. In fact, they argue, "elections are the only form of political participation where every citizen's voice counts equally" (Lister \& Pia, 2008, p 86). In Sweden as well as in other countries the solution to disengagement in politics at the national and local/regional levels has been to make it more 'participatory' through introducing a range of activities such as citizen councils, panels and forums ('democratic innovations' referred to as 'citizen dialogue' in Sweden). However, as many of the attempts to increase people's opportunities to participate are based on self-selection, they may create or exaggerate an imbalance between those who participate and those who do not (de Freitas \& Martin, 2015; Lundell et al., 2016; Urbinati \& Warren, 2008). In Sweden, there is thus a need to pay attention to the weak effect attributed to voting in regional elections and to follow up on who is involved between elections. There is reason to believe that the young and those with a low level of education are less involved the political process (Demokratiutredningen, 2016) and that those not being involved in patient activities are those who have the most to gain, i.e. those with greater healthcare needs (Ocloo \& Matthews, 2016).

Limitations and future research

There are a few limitations to the study. As data on actual participation and impact is not available in official national registries or surveys we had to collect the data with the help from TNS Sifo, Sweden's leading market-research company with extensive experience of societal- and opinion research. Furthermore, we only surveyed activities previously investigated at the local or regional levels and listed in the regions' websites ('known activities'), and we may not have included 
some of "the action that publics take within their health systems" (Stewart, 2016: 122). Our measure of voting participation among those 18 and over in the sample was lower than regional voter turnout in 2014 (76\% compared to 82\%). This may be due to the age distribution of our sample, gender balance or number of foreign born participants. However, our sample does not appear to have a bias towards low-activity individuals as the share taking part in public involvement activities is similar or higher to findings from the only comparable survey carried out in one of 21 the Swedish regions (Bergström, 2012). As very few people seem to engage in certain types of involvement some participant numbers become limited even in a sample of 1,500 individuals (for example only 12 individuals had submitted a citizen suggestion and were able to estimate the impact): hence making confidence intervals broad. It is plausible that we would find higher levels of involvement in a patient population. Our study did not collect data on motivation - why people got involved — and this limits our capacity to interpret the reasons for the patterns of activity that we report. We also did not collect data on actual involvement but rather people's recollection of being involved. Similarly, there is no agreed measure of the impact of involvement and we rely on people's evaluation of the impact of their involvement as this, we argue, is most likely to be linked to a likelihood of being involved in the future. It may very well be the case that it is difficult for those involved to evaluate the impact, and that it is easier in relation to certain involvement activities, potentially individual ones. In addition, it may be easier for people to notice intrinsic impacts such as inclusion or increased self-esteem compared to extrinsic impacts such as health greater system effectiveness. 
There is still little theorising on the motivation of service users to be involved or how this relates to particular types of activities (Birchall \& Simmons, 2004). Important factors mentioned include skills, beliefs about impact and the own capacity, and confidence. Thus, further research is needed to explore how people conceptualise involvement activities and their motivation for getting involved. Furthermore, the extent to which people frame their participation as patients or citizens and how this relates to the type of activity and their assumptions of the impact that this makes on decisions need exploring. A complicating factor discussing this distinction is that 'the patient' is a sub-category of 'the public' and that individuals may bring their more narrow patient perspective into activities that are oriented towards expressing the broader public interest. More focused investigation is also needed of why people perceived their attempt to influence healthcare decisions or provision had little effect. One explanation may be related to the design of involvement activities, and mismatched expectations (Charles \& DeMaio, 1993; Forbat et al., 2009; Hogg, 1999; Warsh, 2014). There are also many examples of malfunctioning involvement, and some professionals and organizations are still threatened by the notion of active involvement (Ocloo \& Matthews, 2016). Lastly, it is crucial to further explore whether there are sociodemographic differences relating to the extent of involvement in different types of activities or how individuals estimate impact (Ocloo \& Matthews, 2016). If involvement impact is unevenly distributed between e.g. sociodemographic groups, involvement policies need to take that into consideration.

\section{Conclusions}


Most people reported being involved as individual patients and overall, our results are consistent with reports about the Swedish welfare state's gradual liberalization and individualization (Lapidus et al., 2015; Olsen, 2013); trends which we also see in other European health systems. Our results also suggest that the Swedish health system, which is based on equity and participation through the regional democratic system (Magnussen, 2009), needs to pay attention to the levels of citizen involvement between elections and the weak effect attributed to voting in regional elections. While levels of involvement are potentially low, there is no systematic evidence of what level of involvement should be expected; whatever the level, involvement is going to increase if people believe their participation makes a difference. Thus, one of the future challenges is to strengthen the support for long-term collective involvement through a range of different activities, which currently engage relatively few, but are estimated to have a comparatively high impact by the participants. To encourage greater involvement in health matters we suggest that impact measures (both intrinsic and extrinsic) building on the recognition that patient and public involvement are distinct are developed and that involvement impact is openly reported and fed back to the participants.

\section{References}

Anderson, W., Florin, D., Gillam, S. and Mountford, L. (2002) Every Voice Counts. Primary Care Organisations and Public Involvement. London: King's Fund.

[Anonymous 2017] Details omitted for double-blind reviewing.

[Anonymous 2013] Details omitted for double-blind reviewing. [Anonymous 2013] Details omitted for double-blind reviewing. 
[Anonymous 2009] Details omitted for double-blind reviewing.

Amnå, E., 2006. Playing with fire? Swedish mobilization for participatory democracy. Journal of European Public Policy. 13(4):587-606.

Anell, A., Glenngård, A.H., \& Merkur, S., 2012. Sweden Health system review. In Health Systems in Transition, 14(5):1-159.

Coulter, A., Ellins, J., 2006. Patient-focused interventions. A review of the evidence. The Health Foundation, London.

Arvidsson, C., Zambon, F., \& Östergren, P.-O., 2015. Taking a participatory approach to development and better health. Examples from the Regions of health Network. WHO Regional Office for Europe, Region Skåne, Regions for Health Network.

Beresford, P., 2013. Beyond the usual suspects. London: Shaping Our Lives.

Bergström, A., 2012. Medborgardemokrati i Skåne [Citizen democracy in Skåne]. Göteborg: SOM-Institutet.

Birchall, J., Simmons, R., 2004. User power. The participation of users in public services. National Counsumer Council.

Brannan, T., John, P., Stoker, G., 2006. Active citizenship and effective public services and programmes: How can we know what really works? Urban Studies, 43, 993-1008.

Brett, J., et al., 2014a. A Systematic Review of the Impact of Patient and Public Involvement on Service Users, Researchers and Communities. The Patient - Patient-Centered Outcomes Research, 7, 387-395.

Brett, J., et al., 2014b. Mapping the impact of patient and public involvement on health and social care research: a systematic review. Health Expectations, 17, 637-650. 
British medical Association (BMA), 20015. Patient and public involvement: a tool kit for GPs.

Busse, R., Blümel, M. 2014. Germany Health system review. Health Systems in

\section{Transition, 2014, 16(2):1-296.}

Charles, C., DeMaio, S., 1993. Lay Participation in Health Care Decision Making: A Conceptual Framework. Journal of Health Politics Policy and Law, 18, 881-904.

Christiaens, W. et al., 2012. Models for citizen and patient involvement in health care policy - Part I: Exploration of their feasibility and acceptability. (No. KCE Reports 195C). Belgian Health Care Knowledge Centre (KCE), Brussels.

Coulter, A., 2005. What do patients and the public want from primary care? BMJ, $331,1199-1201$.

Coulter, A., 2011. Engaging patients in healthcare. Maidenhead, Berkshire, England: McGraw Hill/Open University Press.

Coulter, A., 2006. Patient engagement: Why is it important? In Healthy Democracy: The Future of Involvement in Health and Social Care. Involve and NHS National Centre for Involvement.

Coulter, A., \& Ellins, J., 2006. Patient-focused interventions. A review of the evidence. London: Picker Institute Europe, The Health Foundation.

Crawford, M., Thelwall S., 2003. User Involvement in Change Management: A Review of the Literature. Report to the National Co-ordinating Centre for NHS Service Delivery and Organisation R \& D (NCCSDO). 
de Freitas, C., Martin, G., 2015. Inclusive public participation in health: Policy, practice and theoretical contributions to promote the involvement of marginalised groups in healthcare. Social science \& medicine, 135, 31.

Dent, M., Pahor, M., 2015. Patient involvement in Europe - a comparative framework. Journal of Health Organization and Management, 29, 546555.

Docteur, E., Coulter, A., 2012. Patient-centeredness in Sweden's health system: an assessment and six steps for progress. Solna: Myndigheten för vårdanalys.

European Commission, 2013. Flash Eurobarometer 373. Europeans' engagement in participatory democracy. http://ec.europa.eu/commfrontoffice/publicopinion/flash/fl_373_en.pdf

Florin, D., Dixon, J., 2004. Public involvement in health care. BMJ, 328, 159-161.

Forbat, L., Hubbard, G., \& Kearney, N., 2009. Patient and public involvement: models and muddles. Journal of clinical nursing, 18, 2547-2554.

Forster, R., Kranich, C. 2007. [Patient and public involvement in health care--a comparison between recent english and german policies]. Article in german, English abstract. Gesundheitswesen. 2007 Feb;69(2):98-104.

Garcia-Dominic, O. et al., 2010. Identifying Barriers That Hinder Onsite Parental Involvement in a School-Based Health Promotion Program. Health promotion practice, $11,703-713$.

Greenland, S., Senn, S.J., Rothman, K.J. et al. 2016. Statistical tests, P values, confidence intervals, and power: a guide to misinterpretations. Eur J Epidemiol 31: 337. 
Haarmann, A. 2018. The Evolution and Everyday Practice of Collective Patient

Involvement in Europe An Examination of Policy Processes, Motivations, and Implementations in Four Countries. Cham: Springer International Publishing.

Hirschman, A.O., 1970. Exit, voice, and loyalty: responses to decline in firms, organizations, and states. Cambridge, Mass: Harvard Univ. Press.

Hogg, C., 1999. Patients, power \& politics: from patients to citizens. Thousand Oaks, Calif;London; SAGE.

Härter, M., Müller, H., Dirmaier, I., Donner-Banzhoff, N., Bieber C, Eich, W. 2011. Patient participation and shared decision making in Germany - history, agents and current transfer to practice. Z Evid Fortbild Qual Gesundhwes. 105(4):263-70.

Magnussen, K.V., Saltman R.B., Martinussen P.E,. 2009. Introduction: the Nordic model of health care. In Magnussen, J.P., Vrangbæk, K., Saltman, R.B. (Ed.), Nordic health care systems: recent reforms and current policy challenges. Maidenhead, UK: Open University Press.

$\underline{\text { Kofahl, C., Trojan A., Knesebeck O., Nickel S. 2014. Self-help friendliness: A }}$ German approach for strengthening the cooperation between self-help groups and health care professionals. Soc Sci Med. 123:217-25.

Lapidus, J., 2015. Social Democracy and the Swedish welfare model. Ideational analyses of attitudes towards competition, individualization, privatization. Handelshögskolan vid Göteborgs universitet.

Lister, M., Pia, E., 2008. Citizenship in contemporary Europe. Edinburgh: Edinburgh University Press. 
Litva, A., et al., 2002. 'The public is too subjective': public involvement at different levels of health-care decision making. Social Science \& Medicine, 54, 1825-1837.

Lowndes V, Pratchett L, Stoker G. Diagnosing and Remedying the Failings of Official Participation Schemes: The CLEAR Framework. Social Policy and Society. 2006;5(2):281-91.

Lundell, K., Karjalainen, M., Serup, H., 2016. After the Merger: Do Citizens Want Democratic Innovations? Scandinavian Journal of Public Administration, 20, 3-31.

Magnussen, J.P., Vrangbæk, K., Saltman, R.B., 2009. Nordic health care systems: recent reforms and current policy challenges. Maidenhead, UK: Open University Press.

Martin, S., Boaz, A., 2000. The Modernization and Improvement of Government and Public Services: Public Participation and Citizen-Centred Local Government: Lessons from the Best Value and Better Government for Older People Pilot Programmes. Public Money \& Management, 20, 47-54.

Michels, A.M.B., 2011. Innovations in democratic governance-How does citizen participation contribute to a better democracy? International Review of Administrative Sciences, 77, 275-293.

Mockford, C., et al., 2012. The impact of patient and public involvement on UK NHS health care: a systematic review. International Journal for Quality in Health Care, 24, 28-38.

Ocloo, J., Matthews, R. (2016). From tokenism to empowerment: progressing patient and public involvement in healthcare improvement. BMJ Quality \& Safety 2016;0:1-7 
Olsen, G.M., 2013. What's 'Left' in the 'Garden of Sweden'? International Journal of Health Services, 43, 7-30.

Peeters, Y. and Stiggelbout, A.M. (2010) Health state valuations of patients and the general public analytically compared: A meta-analytical comparison of patient and population health state utilities, Value Health, 13, 2, 306-9.

Pierre, J., 2009. Reinventing Governance, Reinventing Democracy? Policy and Politics, 37, 591.

Pierre, J., Røiseland, A. 2016. Exit and voice in local government reconsidered: A 'choice revolution'? Public Administration, 94(3): 738-753.

Rosén, P., 2006. Public dialogue on healthcare prioritisation. Health policy, 79, 107-116.

$\underline{\text { Rojatz, D., Forster, R. 2017. Self-help organisations as patient representatives in }}$ health care and policy decision-making. Health Policy Oct;121(10):10471052.

Sawicki, P., Bastian H. 2008. German health care: a bit of Bismarck plus more science. BMJ, 7;337:a1997.

Skålén, C., Nordgren, L., Annerbäck, E-M. 2016. Patient complaints about health care in a Swedish County: characteristics and satisfaction after handling Nurs Open. Oct; 3(4): 203-211.

Staniszewska, S., Herron-Marx, S., Mockford, C., 2008. Measuring the impact of patient and public involvement: the need for an evidence base. International Journal for Quality in Health Care, 20, 373-374.

Stewart E. Publics and Their Health Systems. Palgrave Macmillan UK; 2016. Sverige 2014 års demokratiutredning, Låt fler forma framtiden: betänkande. Vol. 2016:5. 2016, Stockholm: Wolters Kluwer. 
Trägårdh, L., 2007. State and civil society in Northern Europe: the Swedish model reconsidered. Oxford;New York; : Berghahn books.

Urbinati, N., Warren, M.E., 2008 The concept of representation in contemporary democratic theory. Annu. Rev. Polit. Sci. 11(1), 387-412.

van Thiel, G., Stolk, P., 2013. Background Paper 8.5. Patient and Citizen Involvement. http://www.who.int/medicines/areas/priority_medicines/BP8_5Stakeh older.pdf

Warsh, J., 2014. PPI: Understanding the Difference Between Patient and Public Involvement. The American Journal of Bioethics, 14, 25-26.

Wildner, M., den Exter, A.P., van der Kraan W.G.M. 2004. The changing role of the individual in social health insurance systems. In Saltman, R.B., Busse, R., Figueras, J., (eds) Social health insurance systems in western Europe. Open University Press, Maidenhead.

Winblad, U., Ringard, Å., 2009. Meeting rising public expectations: the changing roles of patients and citizens. In Magnussen, J.P., Vrangbæk, K., Saltman, R.B. (Ed.), Nordic health care systems: recent reforms and current policy challenges. Maidenhead, UK: Open University Press.

Wolf, C., Joye, D., Smith, T.E.C., Fu, Y-C. (eds) 2016. The SAGE Handbook of Survey Methodology. London, UK: Sage.

The Swedish Agency for Health and Care Services Analysis, 2016. Vården ur befolkningens perspektiv 2016 - en jämförelse mellan Sverige och tio andra länder [Healthcare from the citizen's perspective - a comparison between Sweden and ten other countries]. Based on "The 
Commonwealth Fund's 2016 International Health Policy Survey of Adults in 11 countries". 
Table 1. Sample characteristics

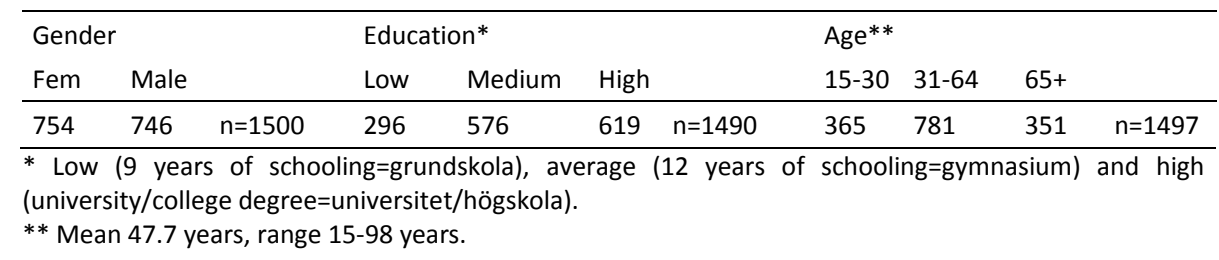




\section{Table 2. Survey questions and response options}

1. There are different ways to actively influence decisions in healthcare and the care provided by health centers, hospitals and the like. Have you been involved in any of the following activities with the purpose to influence health care?

RESPONSE OPTIONS: YES in the last 12 months, YES longer ago, NO.

Involvement activity

Unit and involvement role

a. Making a complaint to a patient board or IVO*

individual; patient

b. Replying to a patient survey

c. Changing your healthcare provider to get better care

individual; patient

individual; patient

d. Talking directly to healthcare professionals about changes

individual; patient

e. Joining or working in a patient organization or similar

Collective; patient

f. Using social media to achieve a change

g. Signing a petition

h. Contacting a local public official

Individual; patient/public

Individual; patient/public

i. Contacting the news media (debate articles etc.)

Individual; patient/public

j. Participating in a demonstration

k. Submitting a citizen suggestion

I. Voting in regional elections Individual; patient/public

m. Contacting a local politician Collective; patient/public

n. Joining or working in a political party

Individual; public

Individual; public

Individual; public

o. Taking part in a citizen council or citizen panel

Collective; public

Collective; public

2. Those who answered YES the last 12 months or YES longer ago were also asked: Do you feel that your attempt to influence health care decisions or provision had an effect?

RESPONSE OPTIONS: 0-10 and Don't know ( $0=$ no effect at all; $10=$ very large effect)

* IVO (Inspektionen för vård och omsorg, the Health and Social Care Inspectorate 
Table 3. Proportion and number taking part in involvement activities last 12 months

\begin{tabular}{lllllllllll}
\hline $\begin{array}{l}\text { Number of } \\
\text { activities }\end{array}$ & & None & $\mathbf{1}$ & $\mathbf{2}$ & $\mathbf{3}$ & $\mathbf{4}$ & $\mathbf{5}$ & $\mathbf{6}$ & $\mathbf{7}$ & $\mathbf{8}$ \\
\hline All activities & $\%$ & 56.9 & 23.4 & 10.0 & 4.5 & 2.5 & 1.5 & 0.5 & 0.4 & 0.3 \\
Citizen & $\mathrm{n}$ & $(854)$ & $(351)$ & $(151)$ & $(67)$ & $(38)$ & $(22)$ & $(7)$ & $(6)$ & $(5)$ \\
activities* & $\%$ & 89.3 & 8.6 & 1.5 & 0.4 & 0.1 & 0.1 & - & - & - \\
\hline
\end{tabular}

Weighted percentages.

* Citizen activities classified as contacting a local public official, contacting a local politician, participating in a demonstration, joining or working in a political party, taking part in a citizen council or citizen panel, and submitting a citizen suggestion. 